\title{
Stereotactic radiotherapy (SBRT) as a sole or salvage therapy in non-small cell lung cancer patients
}

\author{
T. DWORZECKI*, A. IDASIAK, D. SYGULA, U. DWORZECKA, R. SUWINSKI \\ Department of Radiation Oncology and Teaching Hospital, M. Skłodowska-Curie Memorial Cancer Center and Institute of Oncology, Branch \\ Gliwice, Poland
}

${ }^{*}$ Correspondence: $t d w o r z e c k i @ i o . g l i w i c e . p l$

Received August 9, 2011 / Accepted September 12, 2011

\begin{abstract}
The aim of this study is to present evaluation of treatment toxicity and the rate of local control in non-small cell lung cancer patients (NSCLC) treated with stereotactic body radiotherapy (SBRT). The analysis was performed on heterogenous group of 61 NSCLC patients, treated with SBRT between 2005 and 2008. It included 26 patients in clinical stage I, 5 in stage II, 22 in III and 8 in stage IV. In 30 patients SBRT was the only treatment, in 20 patients SBRT was a salvage therapy and in 11 patients SBRT was used as a boost after conventionally fractionated radiotherapy (CRT). The mean age was 67 yrs. Fifteen patients received chemotherapy in the course of treatment. Radiation doses were converted into Linear Quadratic Equivalent Dose at 2Gy per fraction (LQED2). The survival curves were plotted using Kaplan-Maier estimator and analyzed using log-rank test and Cox method. The LQED2 doses administered in stereotactic technique ranged from 8 Gy to 150 Gy and the fraction doses from 5 Gy to $24 \mathrm{~Gy}$. The rate of 2 years local control correlated with LQED2: it was $81 \%$ in a group of patients who received over $110 \mathrm{~Gy}$, compared to $51 \%$ and $33 \%$ in a group of patients who received $60-110$ Gy and less than 30 Gy respectively. Prior radiotherapy and advanced clinical stage correlated with lower doses at SBRT and hence lower rate of local control. The tolerance of SBRT was satisfactory: there was no RTOG grade 3 - 4 toxicity. The results are consistent with findings of other authors and indicate that LQED2 doses delivered by SBRT in the treatment of NSCLC should be higher than 110 Gy whenever clinically feasible. SBRT used as a salvage therapy was less effective, because use of high doses was precluded due to consideration of normal tissue tolerance.
\end{abstract}

Key words: stereotactic body irradiation, lung cancer, reirradiation

Surgery is commonly considered to be a treatment of choice in stage I lung cancer. It provides 5 years local control of about $90 \%$, and a satisfactory 5 years overall survival $[1,2]$. Radiotherapy, which is commonly considered for patients inoperable due to poor performance status or comorbidities carried, until recently, worse prognosis. Percentage of local failure after conventional radiotherapy in stage I non-small cell lung cancer (NSCLC) of lung cancer patients is about $30 \%$ and 5 years overall survival $50 \%$ or less $[3,4]$. Although dose escalation trials using conventionally fractionated radiotherapy indicate that higher doses result in higher percentage of local control, even doses of over 100 Gy did not provide satisfactory local control and were associated with an unacceptable risk of complications [5,6,7]. This phenomenon has been called a "plateau effect" and might be related to repopulation of clonogenic tumor cells between fractions of radiotherapy [8]. Over the last years many investigators showed, however, that higher percentage of local control can be achieved with SBRT - Stereotactic Body Radiotherapy $[9,10]$. The fundamental concept of SBRT is to deliver few high dose fractions within short period of time to small target volume constrained to a tumor with a minimal margin. Usually, several fields are used, with precise dosimetric and positioning verification. SBRT alone is used in patients with early clinical stage, without mediastinal lymphnodes involvement, who cannot undergo surgery due comorbidities, poor clinical performance or to those who refuse surgery. Patients with centrally localized lesions are not the best candidates to SBRT due to tumor's proximity to critical structures $[11,12]$.

The other patients, who do not fulfill those criteria, can be occasionally qualified to SBRT $[13,14,15]$. It, however, entails use of lower dose fractions, in order to minimize the risk of complications. 
This study presents the analysis of treatment outcome in patients with NSCLC treated with SBRT as a sole curative treatment with curative intent, as stereotactic boost after fractionated radiotherapy or as a salvage treatment, after conventional radiotherapy.

\section{Patients and Methods}

Patients characteristics. The analysis includes 61 patients with non-small cell lung cancer (NSCLC) treated between 2005 and 2008 with SBRT. Stage I patients comprised $43 \%(26 / 61)$ of the group, stage II $8 \%$ (5/61), stage III 36\% (22/61) and stage IV 13\% (8/61) (Table 1). Eighty percent $(49 / 61)$ of patients were males. Eighteen patients (30\%) received chemotherapy in the course of their treatment. The age ranged between 48 and 89 years with a median of 69 years. The histopatological diagnosis was provided in $93 \%$ (57/61) of patients; it was squamous cell carcinoma in 57\%, adenocarcinoma in 15\%, and non-small cell carcinoma in $21 \%$, one patient had NOS lung cancer and in three patients the diagnosis was based on imaging only. The follow up ranged from 2 months to 4 years with a median of 16 months.

Selection criteria and fractionation schemes. SBRT as a sole radical treatment was most commonly prescribed in patients with stage I non-small cell lung cancer (NSCLC), in good performance status (Zubrod 0-2), who did not have surgery due to comorbidities or who refused surgical treatment. Tumor diameters were less than $5 \mathrm{~cm}$ in its greatest dimension, and tumor had to be located more than $2 \mathrm{~cm}$ outside the proximal part of bronchial tree. Lymphnodes could not be involved. It was assumed that nodes measuring less than $1 \mathrm{~cm}$ in short axis were not suspected of metastasis. Otherwise, radiologically suspected lymphnodes had to be verified by EBUS or PET. The typical dose delivered in that group of patients was $54 \mathrm{~Gy}$ $60 \mathrm{~Gy}$ in three fractions of $18-20 \mathrm{~Gy}$. The fractionation used in a subgroup treated with SBRT alone is presented in Table 2. Patients with larger or centrally located tumor treated with SBRT usually received smaller doses per fraction. There were two patients with small tumors treated with one single fraction of $24 \mathrm{~Gy}$. Altogether, there were 30 patients treated with SBRT as a sole treatment.

Table 1. Clinical characteristics of patients and its impact on 2-year local control.

\begin{tabular}{|c|c|c|c|c|}
\hline Variable & $\begin{array}{c}\text { Number of patients } \\
(\%)\end{array}$ & 2 year local control & $\begin{array}{c}\text { Statistical significance } \\
\text { p }\end{array}$ & $\begin{array}{c}\text { Relative } \\
\text { Risk }\end{array}$ \\
\hline $\begin{array}{l}\text { Clinical stage: } \\
\text { I and II } \\
\text { III and IV }\end{array}$ & $\begin{array}{l}31(51 \%) \\
30(49 \%) \\
\end{array}$ & $\begin{array}{l}56 \% \\
36 \% \\
\end{array}$ & 0.16 & 1.75 \\
\hline $\begin{array}{l}\text { Age: } \\
>70 \text { years } \\
<70 \text { years }\end{array}$ & $\begin{array}{l}30(49 \%) \\
31(51 \%) \\
\end{array}$ & $\begin{array}{l}55 \% \\
43 \% \\
\end{array}$ & 0.22 & 0.61 \\
\hline $\begin{array}{l}\text { Gender: } \\
\text { Female } \\
\text { Male }\end{array}$ & $\begin{array}{l}12(20 \%) \\
49(80 \%)\end{array}$ & $\begin{array}{l}70 \% \\
41 \% \\
\end{array}$ & 0.55 & 0.74 \\
\hline $\begin{array}{l}\text { total-LQED2-r: } \\
>110 \mathrm{~Gy} \\
60-110 \mathrm{~Gy} \\
<60 \mathrm{~Gy}\end{array}$ & $\begin{array}{l}14(23 \%) \\
17(28 \%) \\
30(49 \%)\end{array}$ & $\begin{array}{l}81 \% \\
51 \% \\
33 \% \\
\end{array}$ & 0.01 & 2.16 \\
\hline $\begin{array}{l}\text { Type of treatment: } \\
\text { Sole SBRT } \\
\text { SBRT as a boost after CR }\end{array}$ & $\begin{array}{l}30(49 \%) \\
11(18 \%)\end{array}$ & $\begin{array}{l}63 \% \\
54 \%\end{array}$ & 0.02 & 1.73 \\
\hline SBRT as a salvage therapy & $20(33 \%)$ & $27 \%$ & & \\
\hline $\begin{array}{l}\text { Chemotherapy as part of treatment: } \\
\text { no } \\
\text { yes }\end{array}$ & $\begin{array}{l}43(70 \%) \\
18(30 \%)\end{array}$ & $\begin{array}{l}58 \% \\
21 \% \\
\end{array}$ & 0.02 & 1.65 \\
\hline $\begin{array}{l}\text { Histopatology: } \\
\text { squamous cell } \\
\text { adenocarcinoma } \\
\text { non-small cell } \\
\text { other }\end{array}$ & $\begin{array}{c}35(57 \%) \\
9(15 \%) \\
13(21 \%) \\
4(7 \%) \\
\end{array}$ & $\begin{array}{l}43 \% \\
22 \% \\
84 \% \\
50 \% \\
\end{array}$ & 0.66 & 0.93 \\
\hline $\begin{array}{l}\text { Tumor volume: } \\
<10 \mathrm{~cm} 3 \\
>10 \mathrm{~cm} 3 \mathrm{i}<100 \mathrm{~cm} 3 \\
>100 \mathrm{~cm} 3\end{array}$ & $\begin{array}{l}11(18 \%) \\
38(63 \%) \\
10(16 \%)\end{array}$ & $\begin{array}{l}55 \% \\
50 \% \\
28 \% \\
\end{array}$ & 0.13 & 1.64 \\
\hline
\end{tabular}


Table 2. Dose-fractionation used in 30 patients treated with SBRT alone.

\begin{tabular}{lcccc}
\hline $\begin{array}{l}\text { Number of } \\
\text { SBRT fractions }\end{array}$ & $\begin{array}{c}\text { Number } \\
\text { of patients }\end{array}$ & $\begin{array}{c}\text { Dose per } \\
\text { fraction used } \\
\text { (median) } \\
\text { Gy }\end{array}$ & $\begin{array}{c}\text { Overall } \\
\text { treatment time } \\
\text { (median) } \\
\text { weeks }\end{array}$ & $\begin{array}{c}\text { LQED2-r } \\
\text { (median) } \\
\text { Gy }\end{array}$ \\
\hline 1 & 4 & $\begin{array}{c}15-24 \\
(22)\end{array}$ & - & $\begin{array}{c}31-68 \\
(59)\end{array}$ \\
\hline 2 & 7 & $10-20$ & $2-6$ & $31-100$ \\
$(16)$ & $(5)$ & $(69)$ \\
\hline 3 & 19 & $\begin{array}{c}14-20 \\
(20)\end{array}$ & $\begin{array}{c}2-31 \\
(5)\end{array}$ & $\begin{array}{c}28-150 \\
(126)\end{array}$ \\
\hline
\end{tabular}

LQED2-r - sum of doses of conventional radiotherapy and SBRT with consideration of repopulation

Overall treatment time - time interval between start of CRT and end of SBRT

SBRT as a form of boost was used in 11 patients. It was administered either to primary tumor before CRT ( 5 patients) or to residual tumor after CRT (6 patients). The SBRT doses in that group of patients were 10Gy-32Gy in one or two fractions (Table 3 ).

The last group of patients had SBRT due to local failure after conventional radiotherapy. There were 20 patients treated in such way and the SBRT doses in those patients ranged from 10-39Gy given in one to three fractions. In all of these patients the LQED from CRT was considered 0 Gy for tumor, because repopulation resulting in recurrence apparently outweighed the effect of dose accumulation from CRT (Table 3).

Irradiation technique. During simulation and treatment patients were immobilized in vacuum-fitted stereotactic body mattress, in supine position. To improve the reproducibility, patients setup was marked on the mattress and corresponding point at patients skin. Breathing motion was assessed by sequential CT scans, which should cover at least one complete respiratory cycle. The sensors fixed with a belt to patients upper abdomen allowed to register the respiratory phase. In the case when tumor breathing motion was smaller than $5 \mathrm{~mm}$ the treatment was delivered with free quiet breathing. Otherwise, respiratory gating technique was used, described in other study from our institution [16]. The respiratory phase with smallest tumor movement was chosen - usually the last $20-30 \%$ of expiratory motion. The GTV was delineated only on CT scans corresponding to the chosen phase of respiratory cycle. The
CTV was generated by adding a $5 \mathrm{~mm}$ margin to GTV, whereas PTV was individual depending on tumor motion in the gated portion of the respiratory phase. During simulation, metaplex markers were placed on the upper abdomen. Their respiratory motion was recorded by infrared videocamera. The signal detected by the videocamera initiated radiation only during the chosen respiratory phase. The dose was prescribed to the $95 \%$ isodose covering $100 \%$ of the PTV.

Tumor response and local control assessment. Local failure was defined as the progression of cancer within irradiated volume (SBRT), distant failure as the recurrence elsewhere. It was assed with the use of CT scans or chest radiograph performed first 3 months after treatment and 6 months thereafter. Subsequent results allowed to assess local control. PET was used to discriminate between late progression and radiation fibrosis, whenever required.

Toxicity of treatment. Toxicity of SBRT was assessed retrospectively and based on symptoms reported by patients during treatment and follow up and scored according to RTOG Criteria. Symptoms that occurred six months or more after treatment were scored as late toxicity. Symptoms reported before treatment or which occurred due to progression were not considered as treatment toxicity.

Statistical analysis. Doses of each fraction of SBRT were converted into Linear Quadratic Equivalent Dose at $2 \mathrm{~Gy}$ per fraction (LQED2) according to the equation: $\mathrm{df}^{\star}[(\mathrm{df}+\alpha / \beta) /(2 \mathrm{~Gy}+\alpha / \beta)]$ [16]. The $\alpha / \beta$ ratio for tumor was assumed to be $10 \mathrm{~Gy}, 2 \mathrm{~Gy}$ is the fraction dose in conventional radiotherapy and $\mathrm{df}$ is dose per fraction in SBRT. The total dose delivered during the entire course of SBRT ( LQED2-SBRT) was calculated as the sum of all its fractions. This allowed comparison of doses delivered in various fractions. The same equation was used to convert doses of fractionated radiotherapy when fraction doses other than $2 \mathrm{~Gy}$ were used, and the result was called LQED2-CRT (Conventional Radiotherapy). The total dose that patients received was the sum of SBRT and conventional radiation called total-LQED2.

Since the schemes differed not only in the total dose delivered but also in the time intervals between the fractions of SBRT and interval SBRT - conventional radiation, the effect of cell repopulation was accounted. Therefore, the dose equivalent of tumor repopulation required to compensate for newly formed clonogens was subtracted from the total-LQED2. The resulting dose was called total-LQED2-r. It was assumed that

Table 3. Dose-fractionation used in 31 patients treated both with CRT and SBRT according to the total dose from CRT.

\begin{tabular}{|c|c|c|c|c|c|}
\hline $\begin{array}{l}\text { Dose from CRT } \\
\text { (median) } \\
\text { Gy }\end{array}$ & Number of patients & $\begin{array}{c}\text { Dose from SBRT } \\
\text { (median) } \\
\text { Gy }\end{array}$ & $\begin{array}{l}\text { No of fractions of SBRT } \\
\text { (median) }\end{array}$ & $\begin{array}{c}\text { Time CR-SBRT } \\
\text { (median) } \\
\text { weeks }\end{array}$ & $\begin{array}{l}\text { LQED-r* } \\
\text { (median) } \\
\text { Gy }\end{array}$ \\
\hline $\begin{array}{l}20-54 \\
(30)\end{array}$ & 13 & $\begin{array}{c}10-36 \\
(20) \\
\end{array}$ & $\begin{array}{l}1-2 \\
(2)\end{array}$ & $\begin{array}{l}1-53 \\
(15) \\
\end{array}$ & $\begin{array}{c}11-84 \\
(53) \\
\end{array}$ \\
\hline $\begin{array}{l}58-72 \\
(66)\end{array}$ & 18 & $\begin{array}{l}6-39 \\
(12)\end{array}$ & $\begin{array}{l}1-3 \\
(1)\end{array}$ & $\begin{array}{c}10-226 \\
(37) \\
\end{array}$ & $\begin{array}{r}8-72 \\
(24,5) \\
\end{array}$ \\
\hline
\end{tabular}

LQED2-r - sum of doses of CRT and SBRT with consideration of repopulation

* The vast heterogeneity in time CRT-SBRT and LQED-r is due to combining patients treated with SBRT as a boost and SBRT for recurrence. 


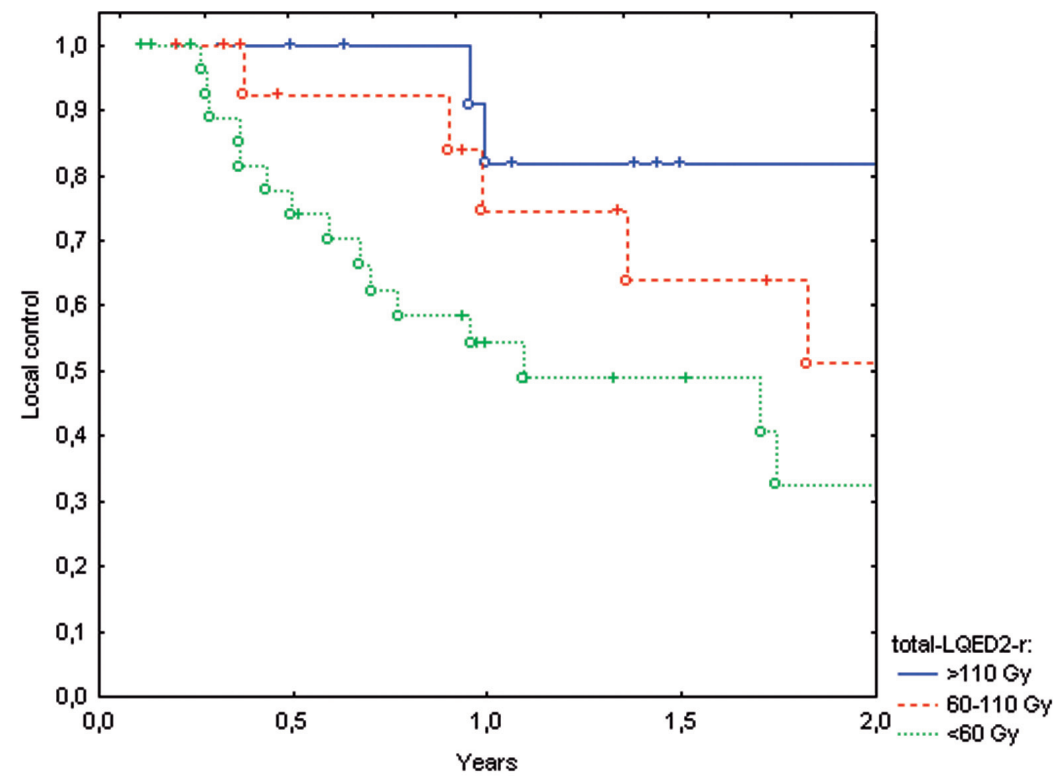

Figure 1. Local control according to total-LQED2-r in the analyzed group of 61 patients $(p=0.01)$.

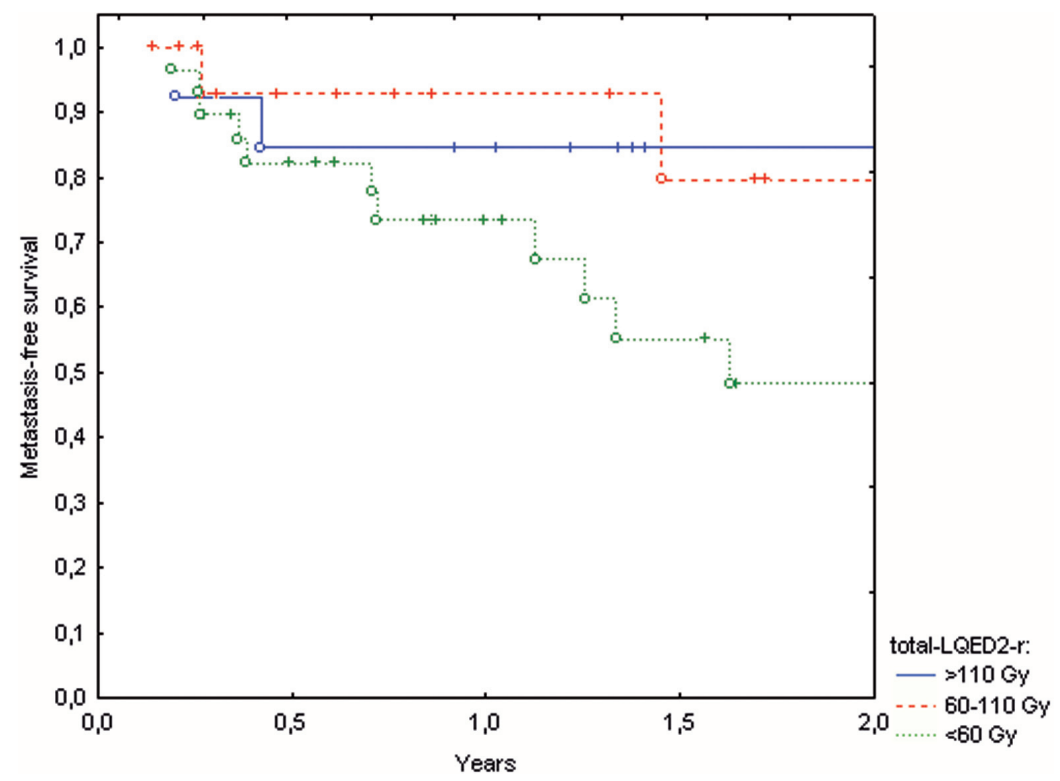

Figure 2. Metastasis-free survival according to total-LQED2-r in the analyzed group of 61 patients $(p=0.14)$.

cancer cell repopulation starts 30 days after the onset of radiotherapy and dose required to compensate this phenomenon is 0,5 Gy per day $[17,18]$. Therefore, $0,5 \mathrm{~Gy}$ was subtracted from the total LQED2 for each day of treatment over 30 days. It applied to both intervals between SBRT and conventional radiotherapy as well as duration of SBRT.

The whole group was divided into three subgroups according to the biologically-equivalent doses received (total-LQED-r): more than 110Gy (14 patients), between 60Gy and 110Gy (17 patients), less than 60Gy (30 patients). Recur- rence-free survival curves were plotted using Kaplan-Meier method. Univariate and multivariate analysis were performed using Cox analysis.

\section{Results}

Local control. Two year local control in the group of patients who received more than $110 \mathrm{~Gy}$ was $81 \%$. It was $51 \%$ in patients who received between 60 and 110Gy and 33\% in those who received less than 60Gy (Fig.1). The differences in local con- 
Table 4. 2-year metastasis-free survival according to clinical characteristics of patients.

\begin{tabular}{|c|c|c|c|c|}
\hline Variable & $\begin{array}{c}\text { Number of patients } \\
(\%)\end{array}$ & $\begin{array}{c}2 \text { year metastasis free } \\
\text { survival }\end{array}$ & $\begin{array}{c}\text { Statistical significance } \\
\mathrm{p}\end{array}$ & Relative Risk \\
\hline \multicolumn{5}{|l|}{ Clinical stage: } \\
\hline I and II & $31(51 \%)$ & $76 \%$ & 0.04 & 3.02 \\
\hline III and IV & $30(49 \%)$ & $55 \%$ & & \\
\hline \multicolumn{5}{|l|}{ Nodal status: } \\
\hline Positive & $42(69 \%)$ & $28 \%$ & 0.01 & 5.63 \\
\hline Negative & $19(31 \%)$ & $81 \%$ & & \\
\hline \multicolumn{5}{|l|}{ Age: } \\
\hline$>70$ years & $30(49 \%)$ & $64 \%$ & 0.32 & 0.61 \\
\hline$<70$ years & $31(51 \%)$ & $68 \%$ & & \\
\hline \multicolumn{5}{|l|}{ Gender: } \\
\hline Female & $12(20 \%)$ & $59 \%$ & 0.55 & 1.38 \\
\hline Male & $49(80 \%)$ & $68 \%$ & & \\
\hline \multicolumn{5}{|l|}{ total-LQED2-r: } \\
\hline$>110 \mathrm{~Gy}$ & $14(23 \%)$ & $81 \%$ & 0.14 & 1.65 \\
\hline $60-110 \mathrm{~Gy}$ & $17(28 \%)$ & $51 \%$ & & \\
\hline$<60 \mathrm{~Gy}$ & $30(49 \%)$ & $33 \%$ & & \\
\hline \multicolumn{5}{|l|}{ Type of treatment: } \\
\hline \multirow[t]{2}{*}{ Sole SBRT } & $30(49 \%)$ & $78 \%$ & & \\
\hline & & & 0.14 & 1.53 \\
\hline SBRT as a boost after CR & $11(18 \%)$ & $58 \%$ & & \\
\hline SBRT as a salvage therapy & $20(33 \%)$ & $59 \%$ & & \\
\hline Chemotherapy as part of treatment: & & & 0.02 & 1.82 \\
\hline no & $43(70 \%)$ & $79 \%$ & & \\
\hline yes & $18(30 \%)$ & $30 \%$ & & \\
\hline \multicolumn{5}{|l|}{ Histopatology: } \\
\hline squamous cell & $35(57 \%)$ & $60 \%$ & & \\
\hline adenocarcinoma & $9(15 \%)$ & $49 \%$ & 0.14 & 0.68 \\
\hline non-small cell & $13(21 \%)$ & $77 \%$ & & \\
\hline other & $4(7 \%)$ & $100 \%$ & & \\
\hline \multicolumn{5}{|l|}{ Tumor volume: } \\
\hline$<10 \mathrm{~cm} 3$ & $11(18 \%)$ & $88 \%$ & 0.26 & 1.57 \\
\hline$>10 \mathrm{~cm} 3 \mathrm{i}<100 \mathrm{~cm} 3$ & $38(63 \%)$ & $77 \%$ & & \\
\hline$>100 \mathrm{~cm} 3$ & $10(16 \%)$ & $55 \%$ & & \\
\hline
\end{tabular}

trol were statistically significant $(\mathrm{p}=0,02)$. The univariate Cox analysis also revealed statistically significant influence of type of treatment ( $\mathrm{p}=0,02, R R=1,73$ ), use of chemotherapy ( $\mathrm{p}=0,02$, $\mathrm{RR}=1,65)$ and total-LQED2-r $(\mathrm{p}=0,01, \mathrm{RR}=2,16)$ (Table 1). On multivariate Cox analysis only total-LQED2-r showed statistical significance. There was no influence of age, gender, tumor volume, histology on two years local control, patients with stage III-IV tended to have lower rates of local control ( $\mathrm{p}=0.16)$.

Distant failure. Distant failure was diagnosed in 15 patients. There was no statistically significant influence of dose delivered, treatment type or tumor volume on distant control. The univariate Cox analysis revealed statistically significant influence of clinical stage, nodal status and use of chemotherapy (Table 4). On multivariate Cox analysis, however, only nodal status turned out statistically significant $(\mathrm{p}=0,01)$. There was no influence of age, gender, tumor volume or histology. Fig. 2 presents the metastasis free survival according to total-LQED2-r.
Treatment toxicity. In general, 29,5\% (18/61) of patients reported symptoms which may have been caused by SBRT. Ten (16\%) of those patients complained of dyspnea or cough of grade 1-2 in RTOG scale (Table 5). There was 1 case of pleural

Table 5. The characteristics of grade 1-2 toxicity observed in a group of 61 patients with lung cancer treated with SBRT. No grade 3-4 toxicity was observed.

\begin{tabular}{llc}
\hline Toxicity & Symptoms & Nr of patients \\
\hline Acute & Dyspnea / caugh & $11 / 61(18 \%)$ \\
& Chest wall pain & $2 / 61(3 \%)$ \\
\hline Late & Dyspnea / caugh & $3 / 61(5 \%)$ \\
& Chest wall pain & $2 / 61(2 \%)$ \\
& Skin pogmentation & $2 / 61(3 \%)$ \\
& Hemoptysis & $1 / 61(2 \%)$ \\
& Pleural effusion & $1 / 61(2 \%)$ \\
\hline
\end{tabular}


effusion with dyspnea and 1 case of hemoptysis, which resolved with time. Four patients complained of chest wall pain, and in two patients skin pigmentation changes were observed. In seven patients symptoms persisted more than six months. Grade 3-4 toxicity was not observed.

\section{Discussion}

In general, the present analysis supports the studies that demonstrate high effectiveness of SBRT in the treatment of NSCLC. It shows that dose escalation without undue treatment time extension, can lead to substantial improvement in local control. This conclusion is supported by other authors $[9,19,20]$. The present analysis indicates that patients with early stage NSCLC, treated by SBRT should receive LQED2 doses higher than 110Gy. It should be emphasized that satisfactory outcomes achieved by SBRT as a sole treatment are considerably better than those after conventional fractionation [21]. The published results indicate that local control after sole SBRT ranges from $70 \%$ to $100 \%[9,22]$. The present study demonstrates that local control in the group of patients who received doses higher than $110 \mathrm{~Gy}$ is within this range. Local control in patients who received lower doses is, however, not satisfactory. Mostly the patients treated due to recurrence of advanced tumors or treated for residual tumor were in this group. Moreover, due to previous radiotherapy many patients could not receive doses rendering high probability of local control. In such cases SBRT had, actually, palliative effect.

We note that all patients treated with SBRT in present series were not considered as candidates for surgery. The comparison of standard surgery and SBRT in operable patients with early stage NSCLC is a subject of on-going studies and must not be considered at present as standard of care. Likewise, surgical resection of recurrent NSCLC should be preferred to SBRT if clinically feasible.

The present results suggest that tolerance of SBRT was acceptable. Although substantial part of the group (30/61) were patients previously treated with conventional radiotherapy, no excessive increase in the treatment toxicity was recorded.

The conclusions from the present study have limitations typical for the retrospective research. The total study sample is relatively small, particularly considering its clinical heterogeneity. Nevertheless, its general outcome indicates that SBRT provides new opportunities to increase local control or delay disease progression in patients with limited therapeutic options.

\section{References:}

[1] SAYNAK M, VEERAMACHANENI NK, HUBBS JL, NAM J, QAQISH BF et al. Local Failure after complete resection of N0-1 non-small cell lung cancer. Lung Cancer 2011; 71: 156165. http://dx.doi.org/10.1016/j.lungcan.2010.06.001

[2] SUGI K, KOBAYASHI S, SUDOU M, SAKANO H, MATSUDA E et al. Long-term prognosis of video-assisted limited surgery for early lung cancer. Eur J Cardiothorac Surg 2010; 37: 456-460

[3] SURA S, GUPTA V, YORKE E, JACKSON A, AMOLS H et al. Intensity-modulated radiation therapy (IMRT) for inoperable non-small cell lung cancer: The Memorial Sloan-Kettering Cancer Center (MSKCC) experience. Radiother Oncol 2008; 87: 17-23 http://dx.doi.org/10.1016/j.radonc.2008.02.005

[4] FANG LC, KOMAKI R, ALLEN P, GUERRERO T, MOHAN $\mathrm{R}$ et al. Comparison of outcomes for patients with medically inoperable Stage I nonâ€"small-cell lung cancer treated with two-dimensional vs. three-dimensional radiotherapy. Int J Radiat Oncol Biol Phys 2006; 66: 108-116 http://dx.doi. org/10.1016/j.ijrobp.2006.04.015

[5] BRADLEY JD, MOUGHAN J, GRAHAM MV, BYHARDT R, GOVINDAN R et al. A Phase I/II Radiation Dose Escalation Study With Concurrent Chemotherapy for Patients With Inoperable Stages I to III Non-Small-Cell Lung Cancer: Phase I Results of RTOG 0117. Int J Radiat Oncol Biol Phys 2010; 77: 367-372. http://dx.doi.org/10.1016/j.ijrobp.2009.04.029

[6] DE RUYSSCHER D, WANDERS R, VAN HAREN E, HOCHSTENBAG M, GERAEDTS W et al. HI-CHART: A Phase I/II Study on the Feasibility of High-Dose Continuous Hyperfractionated Accelerated Radiotherapy in Patients With Inoperable Non-Small-Cell Lung Cancer. Int J Radiat Oncol Biol Phys 2008; 71: 132-138. http://dx.doi.org/10.1016/j.ijrobp.2007.09.048

[7] BBELDERBOS JS, HEEMSBERGEN WD, DE JAEGER K, BAAS P, LEBESQUE JV et al. Final results of a Phase I/II dose escalation trial in non-small-cell lung cancer using three-dimensional conformal radiotherapy. Int J Radiat Oncol Biol Phys 2006; 66: 126-134. http://dx.doi.org/10.1016/ j.ijrobp.2006.04.034

[8] SUWINSKI R, TAYLOR JM, WITHERS HR The effect of heterogeneity in tumor cell kinetics on radiation doseresponse. An exploratory investigation of plateau effect. Radiother Oncol 1999; 50: 57-66. http://dx.doi.org/10.1016/ S0167-8140(99)00014-6

[9] CHI A, LIAO Z, NGUYEN NP, XU J, STEA B et al. Systemic review of the patterns of failure following stereotactic body radiation therapy in early-stage non-small-cell lung cancer: Clinical implications Radiother Oncol 2010; 94: 1-11. http:// dx.doi.org/10.1016/j.radonc.2009.12.008

[10] TIMMERMAN RD, PAULUS R, GALVIN J, MICHALSKI J, STRAUBE W et al. Stereotactic Body Radiation Therapy for Medically Inoperable Early-stage Lung Cancer Patients: Analysis of RTOG 0236. Int J Radiat Oncol Biol Phys 2009; 75: S3. http://dx.doi.org/10.1016/j.ijrobp.2009.07.033

[11] MCGARRY RC, PAPIEZ L, WILLIAMS M, WHITFORD T, TIMMERMAN RD et al. Stereotactic body radiation therapy of early-stage non-small-cell lung carcinoma: Phase I study. Int J Radiat Oncol Biol Phys 2005; 63: 1010-1015. http://dx.doi. org/10.1016/j.ijrobp.2005.03.073

[12] TIMMERMAN R, MCGARRY R, YIANNOUTSOS C, PAPIEZ L, TUDOR $\mathrm{K}$ et al. Excessive toxicity when treating central tumors in a phase II study of stereotactic body radiation therapy for medically inoperable early-stage lung cancer. J Clin Oncol 2006; 24: 4833-4839. http://dx.doi.org/10.1200/ LCO.2006.07.5937 
[13] JOYNER M, SALTER BJ, PAPANIKOLAOU N, FUSS M Stereotactic body radiation therapy for centrally located lung lesions, Acta Oncol 2006; 45: 802-7. http://dx.doi.org/10.1080/ $\underline{02841860600915322}$

[14] SALAZAR OM, SANDHU TS, LATTIN PB, CHANG JH, LEE CK et al. Once-weekly, high-dose stereotactic body radiotherapy for lung cancers: 6-year analysis of 60 early-stage, 42 locally advanced, and 7 metastaic lung cancers. Int J Radiat Oncol Biol Phys 2008; 72: 707-715. http://dx.doi.org/10.1016/ j.ijrobp.2008.01.054

[15] CHEN Y, GUO W, LU Y, ZOU B Dose-individualized stereotactic body radiotherapy for T1-3N0 non-small cell lung cancer: long-term results and efficacy of adjuvant chemotherapy. Radiother Oncol 2008; 88: 351-8. http://dx.doi. org/10.1016/j.radonc.2008.07.013

[16] SUWINSKI R, SLOSAREK K, RUTKOWSKI R, GRZADZIEL A, KOWALSKI A Implementing 4D radiotherapy into clinical practice: the applications of respiratory gated stereotactic radiosurgery for lung tumors. Nowotwory. Journal of Oncology 2006; 56: 242-248

[17] JOINER M, VAN DER KOGEL A Basic Clinical Radiobiology. London: Hodder Arnold, 2009.

[18] WITHERS HR, TAYLOR JM, MACIEJEWSKI B The hazard of accelerated tumor clonogen repopulation during radiotherapy. Acta Oncol 1988; 27: 131-146. http://dx.doi. org/10.3109/02841868809090333

[19] BABA F, SHIBAMOTO Y, OGINO H, MURATA R, SUGIE $\mathrm{C}$ et al. Clinical outcomes of stereotactic body radiotherapy for stage I non-small cell lung cancer using different doses depending on tumor size. Radiation Oncology 2010: 5: 81 http://dx.doi.org/10.1186/1748-717X-5-81

[20] WULF J, BAIER K, MUELLER G, FLENTJE MP DoseResponse in stereotactic irradiation of lung tumors. Radiother Oncol 2005; 77: 83-87. http://dx.doi.org/10.1016/ j.radonc. 2005.09.003

[21] WERNER-WASIK M, SWANN RS, BRADLEY J, GRAHAM $\mathrm{M}$, EMAMI B et al. Increasing tumor volume is predictive of poor overall and progression-free survival: secondary analysis of the radiation therapy oncology group 93-11 phase I-II radiation dose-escalation study in patients with inoperable non-small-cell lung cancer. Int J Radiat Oncol Biol Phys 2008; 70: 385-390. http://dx.doi.org/10.1016/j.ijrobp.2007.06.034

[22] DUNLAP NE, LARNER JM, READ WP, KOZOWER BD, LAU CL et al. Size matters: A comparison of T1 and T2 peripheral non-small-cell lung cancer treated with stereotactic body radiation therapy (SBRT). J. Thorac. Cardiovasc. Surg. 2010; 140: 583-589. http://dx.doi.org/10.1016/ j.jtcvs.2010.01.046 